\title{
Phase behavior of engkabang fat with nonionic surfactants.
}

\begin{abstract}
Phase behavior of engkabang fat was determined through the construction of ternary phase diagrams using nonionic surfactants. Several phase regions appeared in the ternary phase diagrams such as isotropic, homogenous, liquid crystal, two phase and three phase regions. The increase of hydrophilic-lipophilic balance (HLB) values of the nonionic surfactants used gave larger isotropic and homogenous region in the ternary phase diagrams. The combination of engkabang fat:Solubilisant Gamma (2:1) in the ternary phases diagram gave an even larger isotropic and homogenous regions as well as the formation of liquid crystal region.
\end{abstract}

Keyword: Phase behavior; Engkabang fat; Nonionic surfactants. 